\title{
PENGARUH KUALITAS PELAYANAN TERHADAP KEPUASAN PASIEN PADA RUMAH SAKIT UMUM DAERAH PADANGAN KABUPATEN BOJONEGORO
}

\author{
*(Edy Suhartono \\ Fakultas Ekonomi, Universitas Bojonegoro \\ Jl. Lettu Suyitno, No. 2, Kec. Bojonegoro \\ Email: edysuhartono999@gmail.com
}

\begin{abstract}
ABSTRAK
Rumah Sakit Umum Padangan dituntut untuk selalu menjaga kepercayaan konsumen dengan meningkatkan kualitas pelayanan agar kepuasan konsumennya meningkat. Pihak rumah sakit perlu secara cermat menentukan kebutuhan konsumen sebagai upaya untuk memenuhi keinginan dan meningkatkan kepuasan atas pelayanan yang diberikan. Menjalin hubungan dan melakukan penelitian terhadap mereka perlu dilakukan agar pelayanan yang diberikan sesuai dengan yang diharapkan. Data pasien mulai berdiri bulan tahun 2005 sampai dengan tahun 2008 menunjukkan bahwa jumlah setiap bulannya mengalami pasang surut, kadang-kadang naik atau sebaliknya. Hal ini mengindikasikan adanya kemungkinan ketidakpuasan pasien dengan pelayanan yang diberikan. Populasi penelitian ini adalah konsumen pelanggan di Rumah Sakit Umum Daerah Padangan Kabupaten Bojonegoro. Konsumen yang dijadikan sampel adalah pasien yang menggunakan jasa rumah sakit tersebut pada bulan Januari 2009. Cara pengambilan sampel yang digunakan dalam penelitian ini adalah dengan purposive sampling atau sampling bertujuan. Model yang akan digunakan adalah analisis regresi linier berganda. Instrumen Penelitian menggunakan kuesioner dengan pertanyaan tertutup. Metode ini dilakukan secara langsung dengan skala sangat tidak puas, tidak puas, netral, puas, dan sangat puas. Hasil daripenelitian adalah (1) Berdasarkan hipotesis yang pertama bahwa kualitas pelayanan medis, penunjang medis dan paramedis secara simultan atau bersamasama mempunyai pengaruh secara nyata terhadap variabel terikat yaitu kepuasan pasien di Rumah Sakit Umum Daerah Padangan, (2) Faktor medis merupakan faktor dominan yang mempunyai pengaruh secara nyata terhadap variabel terikat yaitu kepuasan pasien di Rumah Sakit Umum Daerah Padangan, (3) Secara parsial kualitas pelayanan penunjang paramedis berpengaruh tidak nyata terhadap kepuasan pasien di Rumah Sakit Umum Daerah Padangan, sedangkan kualitas pelayanan medis dan paramedis mempunyai pengaruh secara nyata terhadap kepuasan pasien di Rumah Sakit Umum Daerah Padangan.
\end{abstract}

Kata kunci: Kualitas pelayanan kesehatan, kepuasan pasien

PENDAHULUAN

Pelayanan kesehatan yang terjangkau oleh seluruh lapisan masyarakat menempati prioritas pertama dalam memenuhi tuntutan masyarakat. Sejalan dengan meningkatnya tingkat pendidikan /pengetahuan dan keadaan sosial ekonomi masyarakat, kebutuhan dan tuntutan masyarakat akan pelayanan 
kesehatan akan terus meningkat. Masyarakat sebagai pengunjung / pengguna jasa menuntut mutu pelayanan yang baik. Penilaian pengguna tergantung pada harapan pengguna. Penilaian tersebut akan menimbulkan kepuasan atau ketidakpuasan dengan segala implikasinya.

Kepuasan pelanggan atau pengguna tempat layanan kesehatan dipengaruhi banyak faktor antara lain medis, penunjang medis, paramedis, prosedur, waktu untuk menunggu dan fasilitas yang ada. Faktor-faktor tersebut harus ditata untuk menghasilkan mutu yang baik sesuai dengan harapan pelanggan, sehingga menimbulkan kepuasan dan kenyamanan pasien. Dengan mengetahui penilaian pelanggan tentang kualitas pelayanan tenaga medis, paramedis, dan penunjang medis, serta kepuasan yang dapat dirasakannya penting sebagai acuan dalam pembenahan pelayanan agar dapat memberikan kepuasan optimal.

Kepuasan pelanggan telah menjadi konsep sentral dalam wacana bisnis dan manajemen (Kotler,2003). Pelanggan umumnya mengharapkan produk berupa barang atau jasa yang dikonsumsi dapat diterima dan dinikmatinya dengan pelayanan yang baik atau memuaskan (Assauri, 2004: 28). Rumah Sakit Umum Daerah Padangan merupakan sebuah lembaga yang bergerak di bidang jasa pelayanan kesehatan. Masalah utama sebagai sebuah lembaga jasa pelayanan kesehatan yang banyak pesaingnya. Oleh karena itu, Rumah Sakit Umum Padangan dituntut untuk selalu menjaga kepercayaan konsumen dengan meningkatkan kualitas pelayanan agar kepuasan konsumennya meningkat. Pihak rumah sakit perlu secara cermat menentukan kebutuhan konsumen sebagai upaya untuk memenuhi keinginan dan meningkatkan kepuasan atas pelayanan yang diberikan. Menjalin hubungan dan melakukan penelitian terhadap mereka perlu dilakukan agar pelayanan yang diberikan sesuai dengan yang diharapkan. Data pasien mulai berdiri bulan tahun 2005 sampai dengan tahun 2008 menunjukkan bahwa jumlah setiap bulannya mengalami pasang surut, kadang-kadang naik atau sebaliknya. Hal ini mengindikasikan adanya kemungkinan ketidakpuasan pasien dengan pelayanan yang diberikan. Oleh karena itu perlu dilakukan kajian tentang pengaruh kualitas pelayanan medis, kualitas pelayanan paramedis dan kualitas pelayanan penunjang medis terhadap kepuasan konsumen di Rumah Sakit Umum Padangan. Hal ini penting untuk memperkirakan keinginan dan harapan konsumen agar pelayanan yang disediakan bisa memberikan kepuasan optimal dan akhirnya konsumen menjadi loyal. Berdasarkan uraian pada latar belakang maka permasalahan dalam penelitian dapat dirumuskan sebagai berikut: (1) Apakah kualitas pelayanan medis, penunjang medis dan paramedis secara bersama-sama berpengaruh terhadap kepuasan Pasien pada Rumah Sakit Umum Daerah Padangan Kabupaten Bojonegoro, (2) Manakah diantara faktor-faktor tersebut yang mempunyai pengaruh dominan terhadap kepuasan Pasien pada Rumah Sakit Umum Daerah Padangan Kabupaten Bojonegoro. Tujuan dari penelitian adalah: (1) Untuk mengetahui apakah kualitas pelayanan medis, penunjang medis dan paramedis secara bersamasama berpengaruh terhadap kepuasan Pasien pada Rumah Sakit Umum Daerah Padangan Kabupaten Bojonegoro, (2) Untuk mengetahui 
manakah diantara faktor-faktor tersebut yang mempunyai pengaruh dominan terhadap kepuasan Pasien pada Rumah Sakit Umum Daerah Padangan Kabupaten Bojonegoro. Manfaat yang diharapkan adalah: (1) Pelayanan dibidang kesehatan dapat menjamin terselenggaranya pelayanan kesehatan yang bermutu di Rumah Sakit Umum daerah Kabupaten Bojonegoro, (2) untuk mengetahui keberhasilan pengelolaan kualitas pelayanan terhadap kepuasan pasien berikut pengembangannya. Hipotesis yang diajukan dalam penelitian adalah: (1) Diduga bahwa kualitas pelayanan medis, penunjang medis dan paramedis secara bersama-sama berpengaruh secara signifikan terhadap kepuasan Pasien pada Rumah Sakit Umum Daerah Padangan Kabupaten Bojonegoro, (2) Diduga bahwa kualitas pelayanan medis mempunyai pengaruh dominan terhadap kepuasan Pasien pada Rumah Sakit Umum Daerah Padangan Kabupaten Bojonegoro.

\section{METODE PENELITIAN}

Populasi penelitian ini adalah konsumen/ pelanggan di Rumah Sakit Umum Daerah Padangan Kabupaten Bojonegoro. Konsumen yang dijadikan sampel adalah pasien yang menggunakan jasa rumah sakit tersebut pada bulan Januari 2009. Cara pengambilan sampel yang digunakan dalam penelitian ini adalah dengan purposive sampling atau sampling bertujuan. Penelitian yang dilakukan ini berhasil mengumpulkan data dari 100 konsumen, terdiri 70 orang pasien rawat jalan dan 30 orang pasien rawat inap. Metode pengumpulan data yang digunakan adalah: Metode Observasi, Metode Interview, dan Metode Kepustakaan. Adapun proses penganalisaan data meliputi penyusunan model, penentuan variabel dan definisi operasional. Model yang akan digunakan adalah analisis regresi linier berganda, dengan alasan dapat mengukur variabel bebas (Independent variable), terhadap variabel terikat. Variabel yang akan digunakan untuk menganalisis kepuasan pasien dalam hal ini variabel bebas terdiri tingkat kualitas pelayanan medis $\left(\mathrm{x}_{1}\right)$, kualitas pelayanan penunjang medis $\left(\mathrm{x}_{2}\right)$, dan kualitas pelayanan paramedis $\left(\mathrm{x}_{3}\right)$, sedang variabel terikatnya yaitu variabel kepuasan pasien (y). Bentuk formulasinya adalah sebagai berikut (Pudjirahardjo, 2003):

$$
\begin{aligned}
& \mathrm{Y}=\mathrm{a}+\mathrm{b}_{1} \mathrm{x}_{1}+\mathrm{b}_{2} \mathrm{x}_{2}+\mathrm{b}_{3} \\
& \mathrm{x}_{3}+\mathrm{e} \quad \ldots(1)
\end{aligned}
$$

Keterangan : $\mathrm{Y}=$ Kepuasan

Pasien, $\mathrm{a}=$ konstanta, $\mathrm{b}=$ koefesiensi regresi berganda, $\mathrm{x}_{1}=$ Kualitas pelayanan medis, $\mathrm{x}_{2}=$ Kualitas pelayanan penunjang medis, $\mathrm{x}_{3}=$ Kualitas pelayanan paramedic, dan $\mathrm{e}=$ Faktor pengganggu. Sedangkan untuk mengetahui apakah kualitas pelayanan medis, kualitas pelayanan penunjang medis dan kualitas pelayanan paramedis secara bersama-sama mempengaruhi kepuasan pasien dan variabel mana yang lebih dominan dan untuk menguji hipotesis yang diajukan, tahap yang akan dilakukan adalah : Dilakukan uji serentak seluruh variabel bebasnya terhadap varibel tidak bebas dengan melalui uji $\mathrm{F}$, yaitu dengan membandingkan nilai $\mathrm{F}$ hitung dengan F tabel. Selanjutnya dicari koefesien determinasinya $\left(\mathrm{r}^{2}\right)$ untuk mengukur ketepatan dari analisis regresi linier berganda yang menunjukkan besarnya variabel bebas dengan variabel terikatnya dengan rumus $r$ Koefisien determinasi

$$
\mathrm{r}=\frac{n \Sigma x y-(\Sigma x)(\Sigma y)}{\sqrt{\left[n \Sigma x^{2}-(\Sigma x)^{2}\right]\left[n \Sigma y^{2}-(\Sigma y)^{2}\right]}} \cdots
$$


Setelah uji serentak, dilakukan uji parsial untuk masing - masing variabel bebas melalui uji $t$. Bila $t_{\text {hitung }}$ $>\mathrm{t}$ tabel maka Ho ditolak dan Hi diterima, artinya ada pengaruh antara variabel bebas dengan tidak bebasnya. Bila $\mathrm{t}$ hitung $<\mathrm{t}$ tabel, maka Ho diterima dan Hi ditolak, artinya tidak ada pengaruh antara variabel bebas dan variabel tidak bebasnya. Kemudian dicari koefesien determinasi parsial ( $r$ ) untuk masing - masing variabel untuk mengetahui variabel mana yang lebih dominan.

Agar tidak terjadi kesalahan yang akan dianalisis, maka di rumuskan definisi operasional yang variabelnya adalah sebagai berikut: (1) Kepuasan pasien adalah perasaan senang atau kecewa yang dialami konsumen setelah membandingkan antara persepsi kinerja (atau hasil) suatu produk dengan harapanharapannya, (2) Kualitas pelayanan adalah tingkat keunggulan pelayanan yang dapat memenuhi keinginan pelanggan yang diberikan oleh tenaga medis, paramedis, dan penunjang medis. (3) Instrumen Penelitian menggunakan kuesioner dengan pertanyaan tertutup. Metode ini dilakukan secara langsung dengan skala sangat tidak puas, tidak puas, netral, puas, dan sangat puas.

\section{HASIL PENELITIAN DAN PEMBAHASAN}

\section{Kepuasan dan Nilai Pelanggan Dalam Pelayanan Kesehatan}

Pokok program peningkatan upaya kesehatan rujukan bertujuan menciptakan jaringan hubungan fungsional antara sarana-sarana kesehatan dengan maksud agar bantuan teknologi, bantuan medik, bantuan sarana, dan bantuan operasional dapat menunjang upaya peningkatan pelayanan kesehatan yang bermutu secara berhasil guna dan berdaya guna. Mutu adalah kepuasan berdasar dari pelanggan. Mutu adalah penentuan pelanggan, bukan ketetapan insinyur, pasar atau ketetapan manajemen. Mutu produk dan jasa adalah seluruh gabungan sifat produk atau jasa pelayanan dari pemasaran, engineering maupun faktoring dan pemeliharaan dimana produk pelayanan dalam penggunaannya akan bertemu dengan harapan pelanggan (Wiyono, 2003:54). Beberapa faktor yang perlu diperhatikan berkaitan dengan fitness for us, yaitu : tersedia, daya tahan atau kehandalan, kemampuan dalam pemeliharaan, kemampuan dalam menghasilkan. (Wiyono,2003:65). Perencanaan mutu terdiri dari identifikasi siapa pelanggan, menetapkan Indetitas kebutuhan pelanggan, mengembangkan keistimewaan produk merespon kebutuhan pelanggan, mengembangkan proses yang mampu menghasilkan keistimewaan produk. Pengendalian mutu terdiri dari kegiatan evaluasi kinerja dan kontrol produk, membandingkan kinerja aktual terhadap tujuan produk. Menurut Wiyono faktor fundamental yang mempengaruhi mutu ada 9 macam yaitu: (1) Men kemajuan teknologi perlu pekerja spesialis yang makin banyak, (2) Money, meningkatnya kompetisi memerlukan penyesuaian biaya yang luar biasa termasuk mutu, (3) Material, bahan makin terbatas dan berbagai jenis materil diperlukan,(4) Mekanis, mekanis perlu penyesuaian seiring dengan kebutuhan kepuasan pelangga, (5) Modern Informasi Methods, kecepatan kemajuan teknologi komputer yang harus selalu diikuti, (6) Markert, tuntutan pasar yang semakin tinggi,(7) Manajerial, tanggung jawab manajemen mutu oleh 
perusahaan,

Motivation, meningkatnya mutu yang kompleks perlu kesadaran mutu bagi pekerjapekerja, dan (9) Monting Product Regiurement, persyaratan produk yang meningkat yang diminta pelanggan perlu penyesuaian mutu terus menerus.

\section{Faktor Kepuasan Pelanggan Pelayanan Kesehatan.}

Kepuasan pelanggan rumah sakit atau organisasi pelayanan kesehatan lain atau kepuasan pasien dipengaruhi banyak faktor, antara lain yang bersangkutan dengan pendekatan dan perilaku petugas, perasaan pasien terutama saat pertama kali datang., mutu informasi yang diterima, seperti apa yang dikerjakan, apa yang dapat diharap, prosedur perjanjian, waktu tunggu, fasilitas umum yang tersedia., fasilitas perhotelan untuk pasien seperti mutu makanan, privacy, dan pengaturan kunjungan, serta Outcome terapi dan perawatan yang diterima.

Produk apapun tidak terlepas dari unsur jasa atau layanan, baik itu jasa sebagai produk inti (jasa murni) maupun jasa sebagai pelengkap (layanan pelanggan). Produk inti umumnya sangat bervariasi antara tipe bisnis yang satu dengan tipe yang lain, tetapi layanan pelengkapannya memiliki kesamaan. Untuk mewujudkan dan mempertahankan kepuasan pelanggan, organisasi jasa harus melakukan empat hal, yaitu: (1) mengidentifikasi siapa pelanggannya. (2) memahami tingkat harapan pelanggan atas kualitas. (3) memahami strategi kualitas layanan pelanggan. Dan (4) memahami siklus pengukuran dan umpan balik dari kepuasan pelanggan. Perusahan perlu mengindentifikasi pelanggannya, pelanggan internal atau pelanggan eksternal, pelanggan bisnis atau konsumen akhir. Kepuasan pelanggan tercapai bila kebutuhan, keinginan, dan pelanggan terpenuhi. Penyebab tidak terpenuhinya harapan pelanggan diantaranya adalah keliru mengkomunikasikan jasa yang diinginkan; keliru menafsirkan signalsignal perusahaan; miskomunikasi dari mulut ke mulut; miskomuniksi penyediaan jasa oleh pesaing; dan kinerja karyawan perusahaan jasa yang buruk.

Strategi kualitas jasa/ layanan harus mencakup empat hal berikut : (1) Atribut Layanan Pelanggan, Pendekatan Untuk Penyempurnaan Kualitas Jasa, (3) Sistem Umpan Balik Untuk Kualitas Layanan Pelanggan, dan (4) Implementasi.

\section{Strategi Kepuasan Pelanggan}

Pada prinsipnya, strategi kepuasan pelanggan menyebabkan para pesaing harus berusaha keras dan memerlukan biaya tinggi dalam usahanya merebut pelanggan suatu perusahaan. Satu hal yang perlu diperhatikan disini adalah bahwa kepuasan pelanggan merupakan strategi jangka panjang yang membutuhkan komitmen, baik menyangkut dana maupun sumber daya manusia.

\section{Konsepsi Menjaga Kualitas Pelayanan}

Menjaga mutu (Quality Assurance-QA) sering diartikan sebagai menjamin mutu atau memastikan mutu. Penilaian mutu tidak hanya pada produk yang dihasilkan, tetapi juga layanan yang diberikan. Kualitas yang baik akan mempengaruhi nilai pelanggan, menimbulkan kenyamanan dan kepuasan pelanggan dengan berbagai implikasinya diantaranya meningkatnya jumlah kunjungan pasien. Untuk meningkatkan mutu 
ditempat layanan diperlukan manajemen mutu untuk menjaga kualitas pelayanan.

\section{Konsepsi Pelayanan di Bidang Kesehatan}

Konsepsi pelayanan di bidang kesehatan terdiri dari:

Penyelenggaraan Pelayanan Kesehatan Dasar, (2) Penyelenggaraan Perbaikan Gizi Masyarakat, (3) Penyelenggaraan Pelayanan Kesehatan Rujukan dan Penunjang, (4) Penyelenggaraan Pemberantasan Penyakit Menular,(5) Penyelenggaraan Promosi Kesehatan, (6) Pencegahan dan Penanggulangan penyalahgunaan Narkotika, Psikotropika dan zat Adiktif ( P3 NAPZA ), (7) Penyelenggaraan Pelayanan Kefarmasian (Obat), (8) Penyediaan Pembiayaan dan Jaminan Kesehatan, (9) Jenis Pelayanan sesuai Kebutuhan.

\section{Analisis Model dan Pembuktian Hipotesis}

$\begin{array}{lcr}\text { Di } & \text { Rumah } & \text { Sakit } \\ \text { Daerah } & \text { Padangan } & \text { Kabupaten } \\ \text { Bojonegoro } & \text { setiap } & \text { tahunnya } \\ \text { mengalami } & \text { perbaikan } & \text { perbaikan }\end{array}$
pelayanan termasuk standart pelayanan agar sesuai dengan perubahan dan keinginan masyarakat. Dengan menggunakan hipotesa atau jawaban sementara bahwa diduga variabelvariabel pelayanan medis, pelayanan penunjang medis dan pelayanan paramedis secara bersama-sama berpengaruh secara signifikan dengan kepuasan pasien di rumah Sakit Umum Padangan Kabupaten Bojonegoro. Berdasarkan hasil penelitian dengan menggunakan SPSS diperoleh hasilnya seperti pada tabel 1 .
Tabel 1. Uji Regresi Linier Berganda

\begin{tabular}{|c|c|c|c|c|}
\hline Variabel & $\begin{array}{c}\text { Koef } \\
\text { isien } \\
\text { Regr } \\
\text { esi }\end{array}$ & $\begin{array}{c}\text { Gala } \\
\mathrm{t} \\
\text { Bak } \\
\mathrm{u}\end{array}$ & $\begin{array}{l}\text { Nil } \\
\text { ai t }\end{array}$ & $\begin{array}{c}\text { Deter } \\
\text { minas } \\
\mathrm{i} \\
\text { Partial }\end{array}$ \\
\hline $\begin{array}{l}\text { Kualitas } \\
\text { Pelayana } \\
\mathrm{n} \text { Medis } \\
\left(\mathrm{X}_{1}\right) \\
\text { K.Pelaya } \\
\text { nan } \\
\text { Penunjan } \\
\mathrm{g} \\
\text { Medis }(\mathrm{X} \\
\text { 2) } \\
\text { Kualitas } \\
\text { Pelayana } \\
\text { nParame } \\
\text { dis }\left(\mathrm{X}_{3}\right)\end{array}$ & $\begin{array}{r}0,60 \\
7 \\
0,08 \\
3 \\
0,40 \\
8\end{array}$ & $\begin{array}{r}0,61 \\
4 \\
0,09 \\
7 \\
0,34 \\
9\end{array}$ & $\begin{array}{r}5,5 \\
56 \\
0,9 \\
86 \\
3,0 \\
98\end{array}$ & $\begin{array}{r}0,355 \\
2 \\
0,017 \\
1 \\
0,146 \\
7\end{array}$ \\
\hline $\begin{array}{l}\text { Konstan } \\
=38,635 \\
\mathrm{~F} \\
=19,076 \\
\mathrm{R}^{2} \\
=0,724 \\
\text { Multiple } \\
\mathrm{R} \quad= \\
0,851\end{array}$ & & & & \\
\hline
\end{tabular}

Persamaan regresi linier berganda akan memperoleh hasil sebagai berikut :

$\mathrm{Y}=38,635+0,607 \mathrm{X}_{1}+0,083$ $\mathrm{X}_{2}+0,408 \mathrm{X}_{3}$

Dari persamaan dapat dijelaskan bahwa koefisien regresi kualitas pelayanan medis sebesar 0,607, artinya jika ada kenaikan satu skor kualitas pelayanan medis akan menaikkan 0,607 skor kepuasan pasien di Rumah Sakit Umum Daerah Padangan, dimana variabel bebas yang lain dianggap konstan atau tetap Koefisien regresi kualitas pelayanan penunjang medis sebesar 0,083 artinya 
jika ada kenaikan satu skor kualitas pelayanan penunjang medis akan menaikkan 0,083 skor kepuasan pasien di Rumah Sakit Umum Daerah Padangan, dimana variabel bebas yang lain dianggap konstan atau tetap. Koefisien regresi kualitas pelayanan paramedis sebesar 0,408 artinya jika ada kenaikan satu skor kualitas pelayanan paramedis akan menaikkan 0,408 skor kepuasan pasien di Rumah Sakit Umum Daerah Padangan, dimana variabel bebas yang lain dianggap konstan atau tetap. Persyaratan dalam metode regresi linier adalah (1) Heteroskedasitas, diperoleh hasil sebagai berikut: Residu kualitas pelayanan medis $\left(\mathrm{X}_{1}\right)$ diperoleh korelasi 0,000, Residu kualitas pelayanan penunjang medis $\left(\mathrm{X}_{2}\right)$ diperoleh korelasi sebesar 0,000,dan Residu kualitas pelauanan paramedis $\left(\mathrm{X}_{3}\right)$ diperoleh korelasi 0,000. Karena nilai korelasi untuk semua variabel sama dengan nol. Jadi dapat disimpulkan persamaan regresi tidak ada gejala heteroskedasitas. (2) Syarat linieritas yang harus dipenuhi. Pada penelitian ini nilai $r^{2}=0,724$. jadi nilai linieritasnya yaitu ei $=1-0,724=0,276$. Karena hasil dari pada koefisien determinan adalah lebih besar dari nilai residual yaitu $0,724>0,276$ maka persamaan regresi linier berganda dalam model analisa penelitian ini sudah linier,(3) Autokorelasi, dari hasil penelitian diperoleh nilai $\mathrm{dL}=1,2756$, $\mathrm{dU}=1,7780$. Nilai $D$. witson 0,194 , maka $3-1,053=1,947 \quad>d U=1,778$ berarti tidak ada autokorelasi pada model

\section{Analisa dan Pengujian Hipotesa}

Diperoleh hasil uji $\mathrm{F}$ dengan $=0,05$, adalah $\mathrm{F}$ hitung $=19,076$ dengan $F$ tabel $=1,68$. Karena $F$ hitung $>\mathrm{F}$ tabel maka $\mathrm{H}_{\mathrm{o}}$ ditolak. Oleh karena $\mathrm{H}_{\mathrm{o}}$ ditolak dan $\mathrm{H}_{\mathrm{i}}$ diterima, berarti secara simultan variabel bebas yaitu kualitas pelayanan medis, kualitas pelayanan penunjang medis kualitas pelayanan paramedis berpengaruh secara nyata terhadap variabel terikat yaitu kepuasan pasien di RSUD Padangan. Nilai koefisien determasi $\left(r^{2}\right)$ dimana hasil perhitungan dari lampiran sebesar 0,724 yang berarti kualitas pelayanan medis $\left(\mathrm{X}_{1}\right)$, kualitas pelayanan penunjang medis $\left(\mathrm{X}_{2}\right)$, kualitas pelayanan paramedis $\left(\mathrm{X}_{3}\right)$, dapat menjelaskan variabel terikat kepuasan pasien $(\mathrm{Y})=72,4 \%$ sedangkan sisanya $=27,6 \%$ dijelaskan variabel lain yang tidak dimasukkan dalam model. Untuk mengetahui keeratan hubungan variabel bebas dengan variabel terikat maka dapat dilihat nilai $r$ multiple 0,851 yang berarti bahwa hubungan variabel bebas dengan variabel terikat adalah kuat.

Selanjutnya untuk mengetahui pengaruh variabel bebas secara parsial terhadap variabel terikat digunakan analisis uji t. (1) Hasil pengujian untuk kualitas pelayanan medis berpengaruh nyata terhadap kepuasan pasien adalah: $\mathrm{t}_{\text {hitung }}=5,556$ dengan $\mathrm{t}$ tabel $=1,6552$. karena $\mathrm{t}_{\text {hitung }}>\mathrm{t}$ tabel maka Ho ditolak. Maka Secara parsial kualitas pelayanan medis berpengaruh nyata terhadap kepuasan pasien. Hal ini menunjukkan bahwa jika ada perubahan kualitas pelayanan medis, maka ada perubahan kepuasan pasien di Rumah Sakit Umum Daerah Padangan. Nilai $r^{2}$ parsial untuk kualitas pelayanan medis sebesar 0,3552 berarti bahwa variabel kualitas pelayanan medis mampu menjelaskan variabel kepuasan pasien di Rumah Sakit Umum Daerah Padangan sebesar 35,53\%. (2) Hasil pengujian untuk kualitas pelayanan penunjang medis berpengaruh nyata terhadap kepuasan pasien adalah $\mathrm{t}_{\text {hitung }}$ $=0,986$ dengan $\mathrm{t}_{\text {tabel }}=1,6552$. karena $\mathrm{t}$ hitung $<\mathrm{t}_{\text {tabel }}$ maka Ho di terima. Secara 
parsial kualitas pelayanan penunjang medis berpengaruh tidak nyata terhadap kepuasan pasien. Nilai $\mathrm{r}^{2}$ parsial $=0,0171$ berarti kualitas pelayanan penunjang paramedis hanya mampu menjelaskan kepuasan pasien $1,71 \%$. Hasil pengujian untuk kualitas pelayanan paramedic berpengaruh nyata terhadap kepuasan pasien adalah $\mathrm{t}_{\text {hitung }}=3,098$ dengan $\mathrm{t}$ tabel $=1,6552$. karena $t_{\text {hitung }}>t_{\text {tabel }}$ maka Ho ditolak. Sehingga secara parsial kualitas pelayanan paramedis berpengaruh nyata terhadap kepuasan pasien di Rumah Sakit Umum Daerah Padangan. Hal ini menunjukkan bahwa jika ada perubahan pada kualitas pelayanan paramedis, maka ada perubahan pada kepuasan pasien di Rumah Sakit Umum Daerah Padangan. Nilai $r^{2}$ parsial untuk kualitas pelayanan paramedis $=0,1467$, berarti variabel kualitas pelayanan paramedis mampu menjelaskan variabel kepuasan pasien di Rumah Sakit Umum Daerah Padangan sebesar 14,67\%.

\section{KESIMPULAN DAN SARAN}

Dari hasil penelitian dan pembahasan diatas maka dapat ditarik suatu kesimpulan sebagai berikut: (1) Ketiga faktor yang mempengaruhi kepuasan pasien di rumah sakit umum daerah padangan adalah kualitas pelayanan medis, kualitas pelayanan penunjang medis dan kualitas pelayanan paramedic,(2) ada hubungan kuat dan positif antara faktor kualitas pelayanan medis, kualitas pelayanan penunjang medis dan kualitas pelayanan paramedis terhadap kepuasan pasien di rumah sakit umum daerah padangan. (3) dengan menggunakan uji $\mathrm{F}$ menunjukkan adanya pengaruh secara nyata antara kualitas pelayanan medis $\left(\mathrm{X}_{1}\right)$ kualitas pelayanan penunjang medis $\left(\mathrm{X}_{2}\right)$, kualitas pelayanan paramedis $\left(\mathrm{X}_{4}\right)$, dengan kepuasan pasien di rumah sakit umum daerah Padangan. Diperleh koefisien determasi $\left(\mathrm{R}^{2}\right)$ sebesar 0,724, berarti $72,4 \%$ kepuasan pasien disebabkan karena kualitas pelayanan medis, penunjang medis dan paramedis dan sisanya $27,6 \%$ disebabkan oleh faktor lain yang tidak dimasukkan dalam model penelitian ini. Sedang $\mathrm{R}$ multiplenya sebesar 0,851 yang berarti bahwa hubungan variabel bebas dengan variabel terikat adalah sangat kuat. (4) Variabel bebas kualitas pelayanan medis $\left(\mathrm{X}_{1}\right)$ berpengaruh secara nyata terhadap variabel terikat kepuasan pasien di rumah sakit umum daerah padangan, Variabel bebas kualitas pelayanan paramedic $\left(\mathrm{X}_{3}\right)$ berpengaruh secara nyata terhadap variabel terikat kepuasan pasien di rumah sakit umum daerah padangan.

\section{DAFTAR PUSTAKA}

Assauri, Sofjan .2003.Customer Service yang Baik Landasan Pencapaian Customer Satisfaction dalam Usahawan, Jakarta

Kotler, Philip .2003.Manajemen Pemasaran Jilid I dan 2 (Terjemahan Benjamin Molan). Jakarta: Prenhallindo

Pudjirahardjo, widodo J.,dkk. 2003. Metode Penelitian dan Statistik

Terapan. Surabaya : Airlangga University Press.

Santoso, Singgih. 2000. SPSS (Statistical Product and Service Solution). Jakarta : PT. Elex Media Komputindo.

Wiyono Djoko.2004. Manajemen Mutu Pelayanan Kesehatan. Surabaya : Airlangga University Pers.

Wiyono Djoko. 2005. Standart Pelayanan Minimal Bidang 
Kesehatan.Surabaya : Airlangga University Pers. 